\title{
Impact of Repair Costs on Company Performance: Technical-Economic Analysis between Two Locomotive Engines DL07 and DM04
}

\author{
Ahcène AKNI \\ LITE Laboratory, Université Frères Mentouri, Constantine 1, Algeria, akniahcene@yahoo.fr \\ Rachid CHAIB \\ LITE Laboratory, Université Frères Mentouri, Constantine 1, Algeria, $\underline{\text { rchaib@umc.edu.dz }}$ \\ Abdelaziz KAHLOUCHE \\ LITE Laboratory, Université Frères Mentouri, Constantine 1, Algeria, kahloucheaziz@yahoo.fr \\ Ion VERZEA \\ “Gheorghe Asachi” Technical University, Iasi 700050, Romania, ion.verzea@academic.tuiasi.ro
}

\begin{abstract}
Today, the company operates in a strong competitive environment where financial concerns are very pronounced and the maintenance function is no exception to this rule of cost reduction. Moreover, it is more ethical than legislative to be satisfied with technical and economic performance without taking into account environmental constraints. As a result, globalization has pushed the Algerian industry towards a direct confrontation in terms of operating safety, profitability and competitiveness, while respecting the protection of the environment in the various branches of industry, particularly in rail transport. An important part of this upgrade is the improvement of the RAMS concept and its application at the level of the different industrial structures. The lack of reliable data and efficient data processing tools, as well as maintenance management methods, has long reduced the maintenance function to troubleshooting tasks, resulting in subsequent high costs such as business performance is not obvious. Thus, the maintenance service must be established as a key player in competitiveness to engage in a quality approach, in particular to determine the performance compatible with the possibilities of the equipment (age, operation, etc.), or even its renewal. Our work is based on a technical-economic analysis between two locomotive engines, the DL07 and the DM04, to determine its operating performance, which is subject to strict reliability, availability and safety objectives while using methods specific to field of reliability. Thus, the estimate of the residual time of operation before the failure of a piece of equipment must make it possible to avoid unnecessary maintenance expenses. This study is based on the evaluation of the number of stops of two engines during five years of operation, an analysis of the different repairs of the two engines with respect to their frequencies and their costs, ended by a comparative study between these two engines in terms of reliability indicator and repair costs.
\end{abstract}

\section{Keywords}

RAMS, maintenance cost, failure, prognosis, rail, quality and operating performance

\section{Introduction}

The complexity of technical systems has led industry and the scientific community to look for new and original solutions that can make these systems more efficient, more competitive and more secure [1]. Today, the company operates in a strong competitive environment where financial concerns are very pronounced and the maintenance function is no exception to this rule of cost reduction. In addition, it is no longer sufficient to be satisfied with technical and economic performance, but it becomes necessary, even mandatory, to take into account environmental constraints. To achieve these objectives, it is not only repair or repair at the lowest cost or repair in the shortest possible time. It is also not keeping the facilities running at all costs or ensuring high operating safety, no matter what, to achieve maximum availability but unprofitable. Thus, throughout the production life, the maintenance monitors the equipment, monitors its degradation and upgrades it with a performance check. At the end of its life, maintenance first proposes a reduction in performance compatible with the possibilities of the equipment and finally its renewal. 
Many research works are directed towards the setting of the parameters of an adequate maintenance policy by looking for the simplest solutions. Thus, the ratio that will encompass all these aspects of maintenance will be:

$$
\frac{\text { Total cost (purchase and maintenance) }+ \text { Loss of production }}{\text { Service rendered }}=\text { must be minimum }
$$

For this, the activity of the maintenance staff has also evolved to combine the technological, organizational and relational skills that play a very important role in any service or production structure [2]. In addition, it is important to emphasize that the dysfunction is a normal event, and even expected. From now on, the maintenance concept must be established as a key player to ensure quality, competitiveness, operational safety, safety and even the protection of the environment. However, estimating the amount of time it takes to operate a device before a device fails should avoid unnecessary maintenance costs. Thus, the industrial prognosis proves to be a key activity, promising not to incur inopportune maintenance costs, or even optimize maintenance strategies. It is becoming a research theme in its own right and is becoming increasingly visible within the scientific community [3], a goal that is targeted in this work.

\section{Methodology of Work}

The purpose of the maintenance is to limit the effects of the disturbances mentioned above in order to be able to meet the requirements that ensure the quality and the best performance compatible with the possibilities of the equipment. To do this, several approaches have been proposed in the literature and the tools implemented depend mainly on the nature of the data and knowledge available to build a model of behaviour of the real system including the phenomenon of degradation. In this work, we chose to focus work on a data-driven approach. Thus, and to arrive at determining the performances compatible with the possibilities of the equipment answering to the needs of the exploitation, it is necessary beforehand to know the reliability of the equipment or the history of the breakdowns during a certain period of its exploitation $[4,5,6]$. This information can be obtained in three ways depending on the nature of the available data as shown in Figure 1, i.e. [7, 8]:

- Physical models of failure;

- System Monitoring (Conditional Maintenance);

- Use feedback.

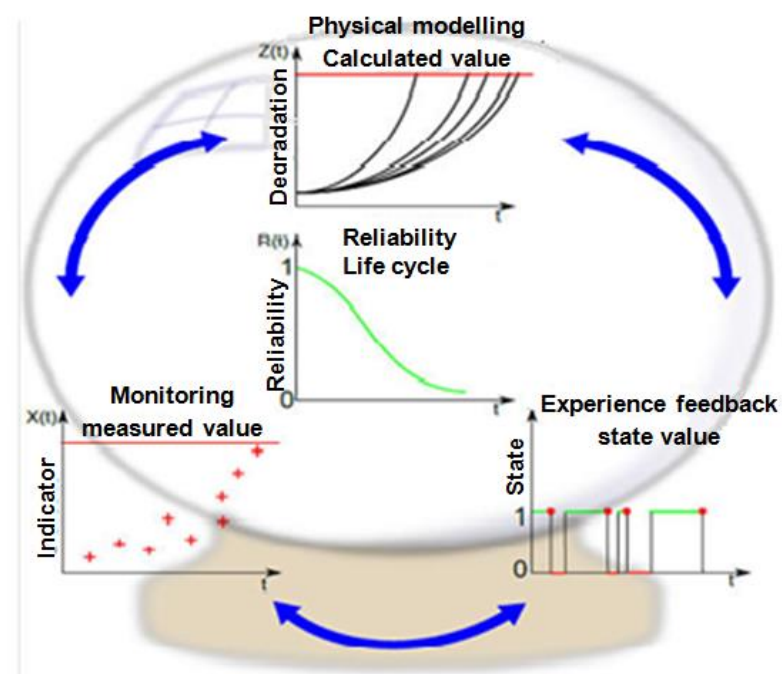

Fig. 1. Approaches to Achieving Reliability [9]

In this work, we contribute to the improvement of maintenance efficiency by using the feedback approach based on historical fault files in a manufacturing workshop. This approach has allowed us to identify appropriate actions that meet operational expectations [10]. Then complete our study by a technical-economic comparison for this pronounced on the spring of the two locomotives. 


\section{Description and Operation of a Locomotive}

The SMK-SNTF depot is responsible for the minor periodic and curative maintenance of locomotives and shunter, Figure 2. It consists of five services to properly organize the work and to maintain the equipment [11].

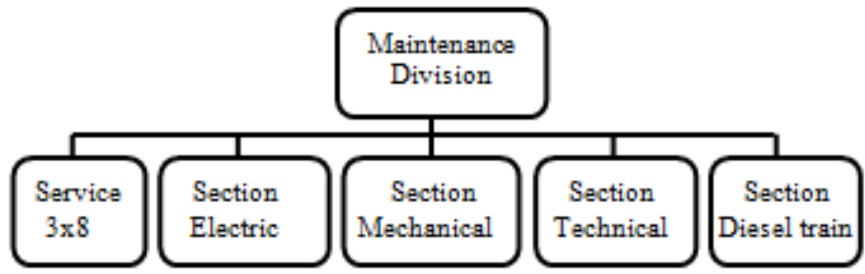

Fig. 2. Flowchart of SMK-SNTF maintenance division Constantine

Diesel locomotives are machines whose traction power comes from an internal diesel engine. There are several types, depending on how the power supplied by the engine is transmitted to the wheels [9].

The types of diesel electric locomotives differ from the point of view of power and performance, but their operating principles are identical. The diagram below (Figure 3) gives an overall idea about the different components of the locomotives.

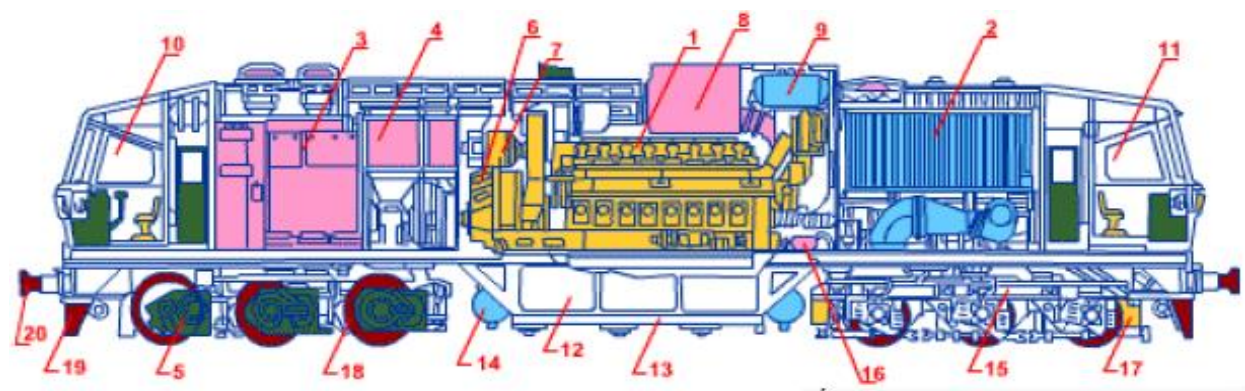

Fig. 3. A Diesel locomotive

1. Diesel engine; 2. Radiator; 3. High voltage; 4. Rectifier; 5. Electric motor traction; 6. Generator; 7. Starter generator;

8. Quiet exhaust; 9. Hold water; 10. Cabin before driving; 11. Cabin rear driving; 12. Electric accumulator; 13. Diesel tank; 14. Pressurized air; 15. Bogie; 16. Fuel pump; 17. Sandpit; 18. Axle; 19. Pare-oxen; 20. Buffer

\section{Calculation of Reliability Indicators}

Dependability has become a major objective, since it is directly related to the evaluation of the performance of industrial systems [12]. In addition, it represents all of a product's capabilities, which enable it to have specified functional performance, at the right time, for the intended duration, which can be classified into four groups [13], Figure 4:

- Limit the number of failures (improve reliability);

- Repair and maintain by respecting the specifications to improve the maintainability;

- Master production (act on availability);

- Protect people, the environment and property (ensure safety).

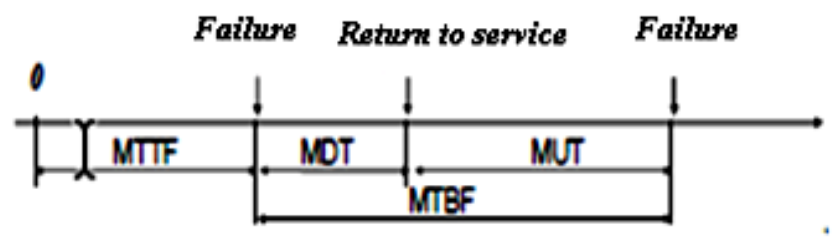

Fig. 4. Concept of dependability

\section{Presentation of Data}

The maintenance division - Sidi Mabrouk depot (Constantine) registers a large number of Emergency Request (DS) for the machines. Figure 5 shows the number of stops for both types, the year 2015 records the maximum number of stops compared to other years, for that we are interested in this analysis of the operation of DM04 and DL07 engines during the year 2015-2019. 
RECENT, Vol. 21, no. 1(60), 2020

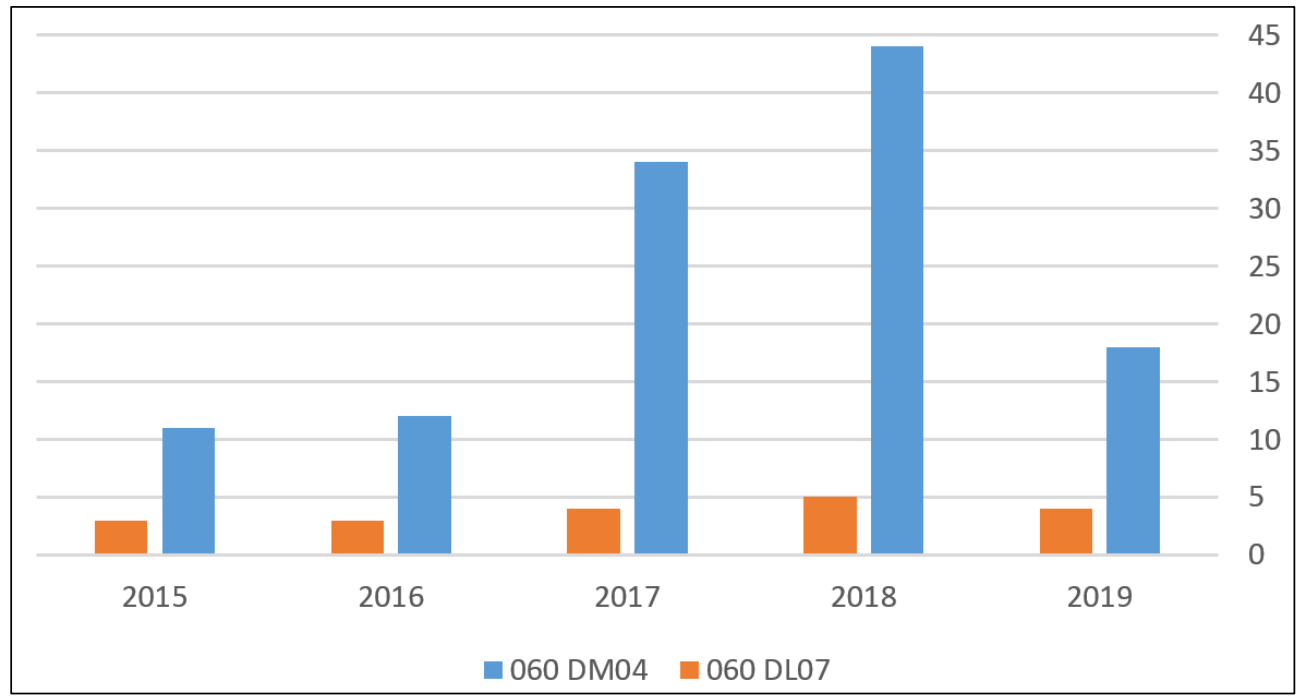

Fig. 5. Number of stops on DM04 and DL07 engines

Figures 6 and 7 illustrate the types of repair suffered by the DM04 and DL07 engines with its frequencies during the period 2018-2019, the maintenance actions or intervention which has a high percentage $(80 \%)$ was found in the case head change, full of oil and change of injectors.

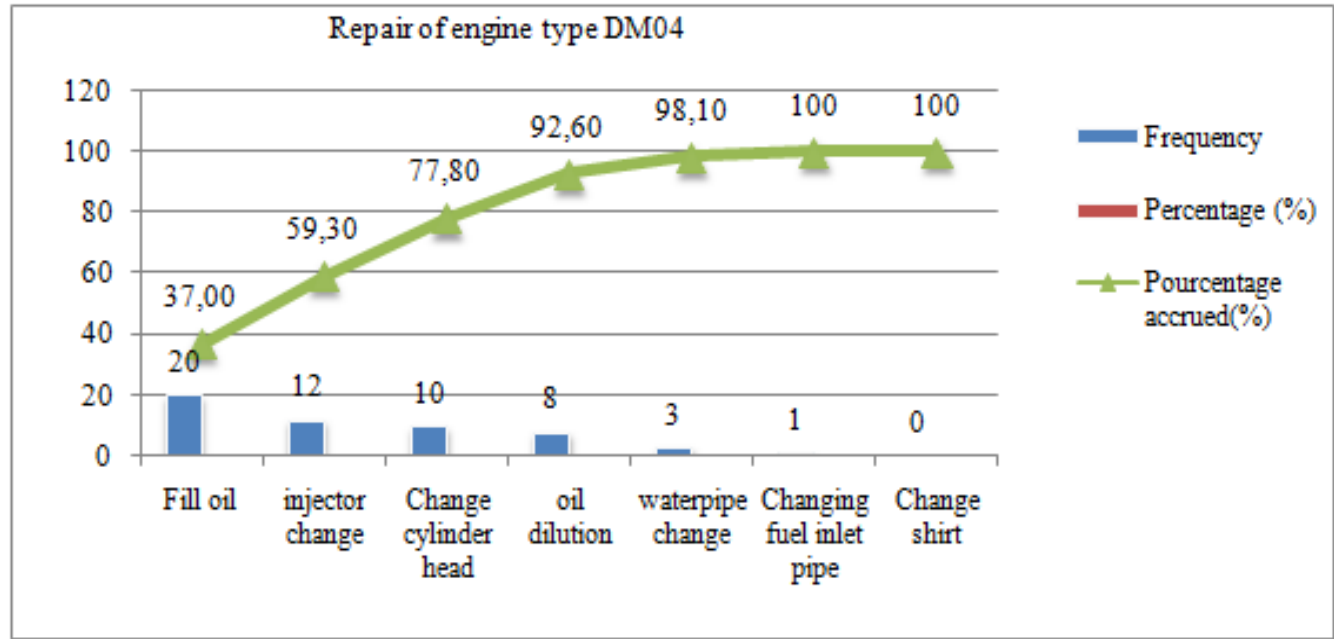

Fig. 6. Repairs of engine type DM04

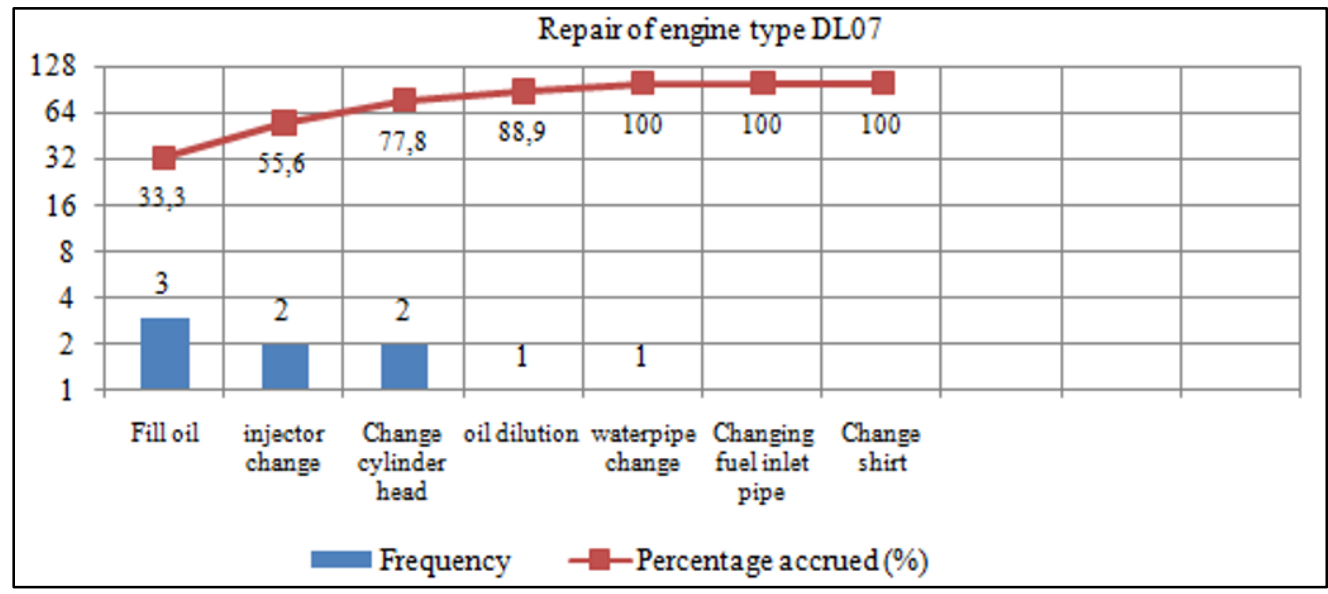

Fig. 7. Repairs of engine type DL07 


\subsection{Determining operating parameters}

\section{Engine type DM04}

Operating Parameters: The figure below (Figure 8) shows the successive operating states of the engine type DM04 for one year. T is the duration operation of the engine type DM04 before the first failure: Mean Time To Failure (MTTF) is a very basic measure of reliability used for non-repairable systems. It represents the length of time that an item is expected to last in operation until it fails.

$\mathrm{MTTF}=60$ days.

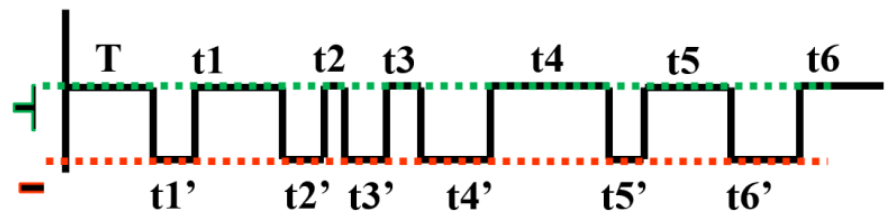

Fig. 8. The operating states diagram of the DM04

The figure 9 shows the duration of proper operation and non-operation as well as the various repairs made during 60 days.

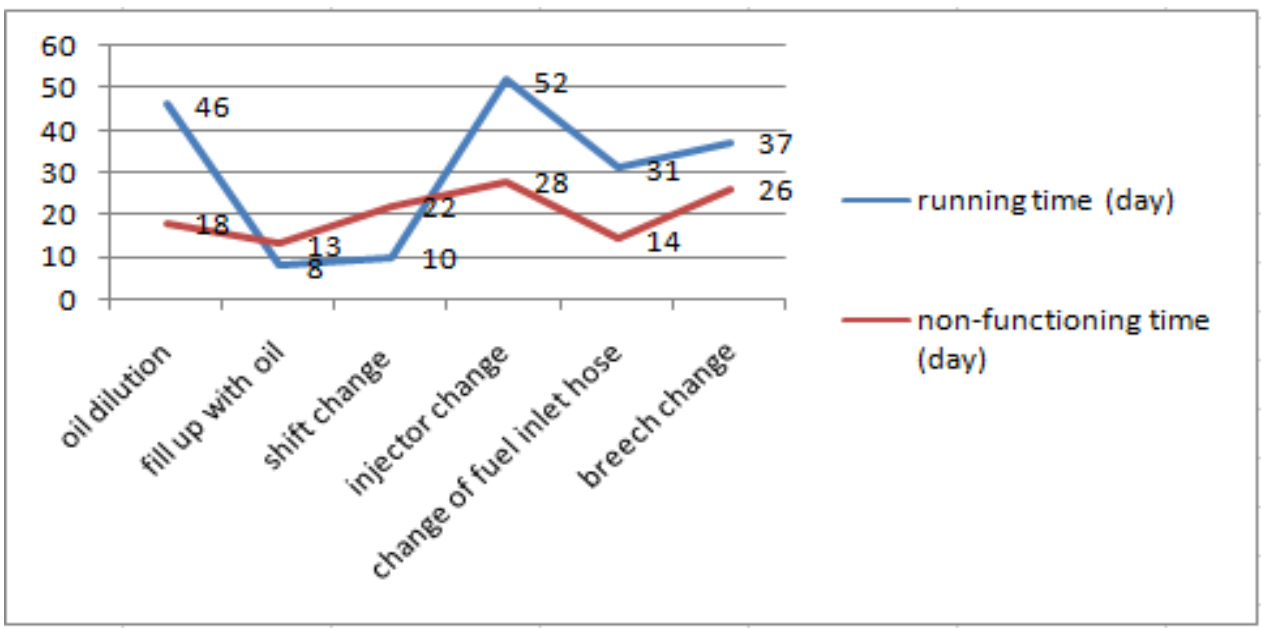

Fig. 9. Time of running and non-functioning of the engine type DM04

Calculation of repair costs: The Company estimates that the hour of work costs 500 DZD (Algerian dinar). In what follows, we calculate the downtime resulting from failures during the time studied as well as the repair cost that can be solved by the expression below:

$$
\text { Repair cost }=\text { Cost of downtime } / \text { year }+ \text { Total price of parts }
$$

The DM04 engine consumes 2496 l of oil for a year.

In Figure 10 are presented the repair costs of the various failures of the DM04 engine.

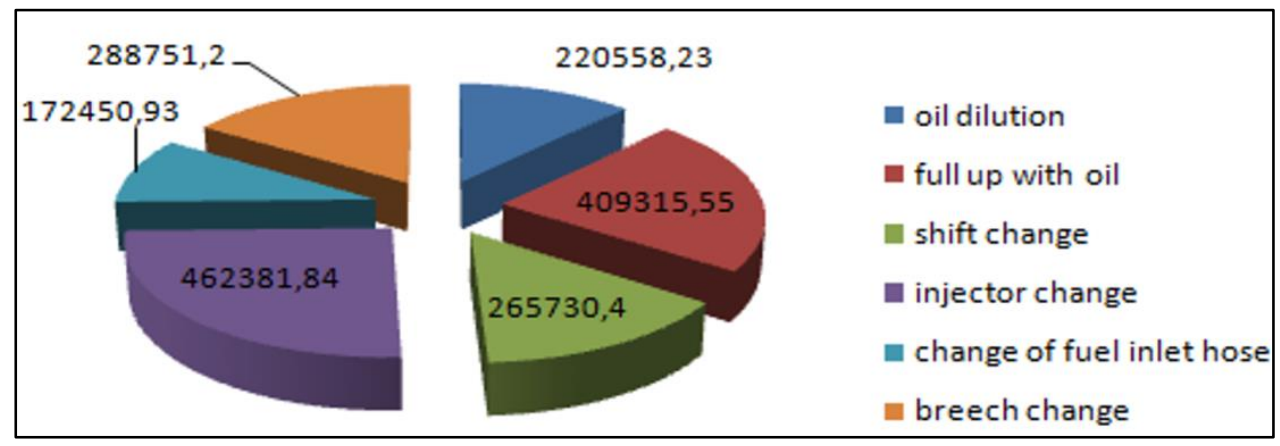

Fig. 10. Repair costs for engine type DM04, in DZD 
RECENT, Vol. 21, no. 1(60), 2020

To realize our study, we took the engine of a different locomotive, type DL07 in order to make a comparison and define the reliability of the engine.

\section{Engine type DL07}

Operating parameters: The figure below (Figure 11) shows the operating conditions of the engine type DL07 during the period 2015/2016. T is the operating time of the DL07 type motor before the first failure: $\mathrm{MTTF}=180$ days.

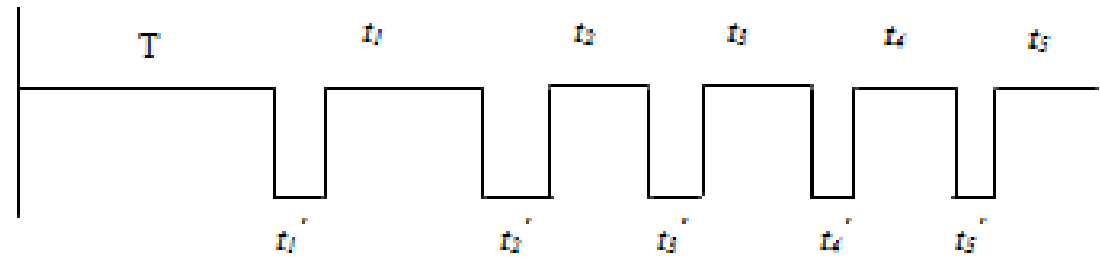

Fig. 11. Representative diagram of the operating states of the engine type DL07

The figure 12 shows the duration of proper operation and non-operation as well as the various repairs made during 180 days.

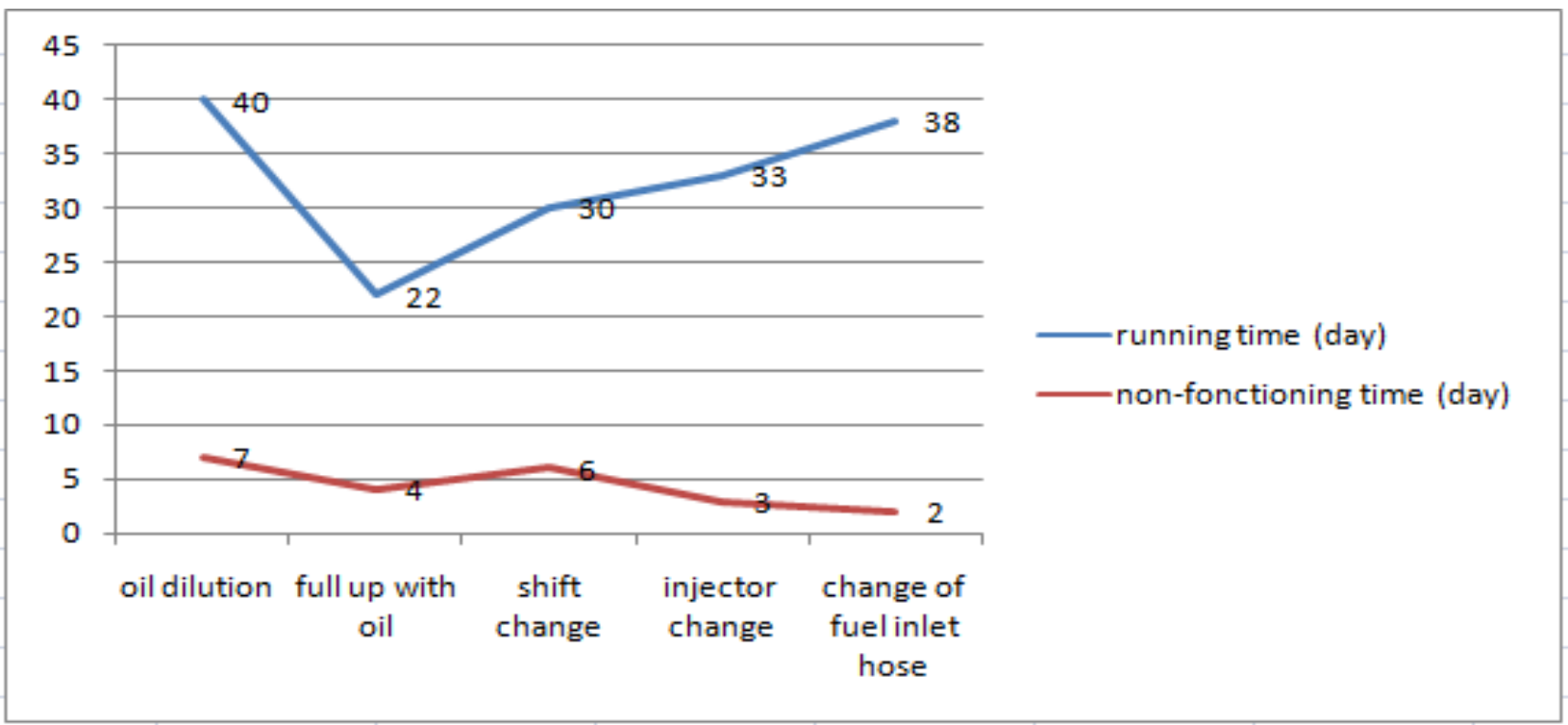

Fig. 12. Time of running and non- functioning of the engine type DL07

Calculation of repair costs: The DL07 engine consumes $120 \mathrm{l}$ for one year.

The calculation of repair costs for the second type is presented in Figure 13.
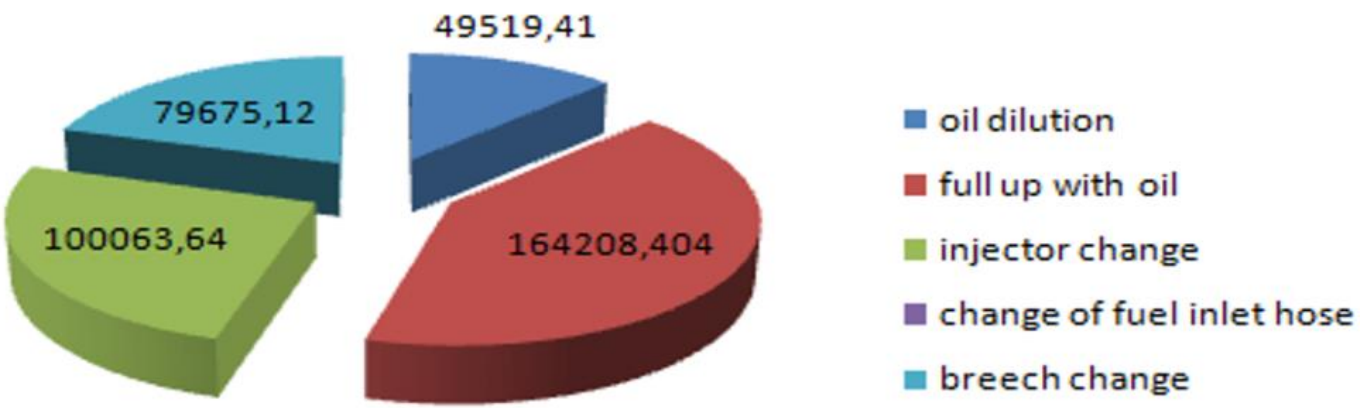

Fig. 13. Repair costs for engine type DM07, in DZD

The results of the reliability indicators of the two locomotives are respectively summarized in Table 2 . 
RECENT, Vol. 21, no. 1(60), 2020

Table 2. Indicators of reliability of the two engines

\begin{tabular}{|c|c|c|c|}
\hline \multirow[b]{2}{*}{ Indicators of reliability } & \multirow[b]{2}{*}{ Expression } & \multicolumn{2}{|c|}{ Values } \\
\hline & & DM04 & DL07 \\
\hline The average repair time & MTTR $=\left(t_{1}^{\prime}+t_{2}^{\prime}+t^{\prime}{ }_{3}+t_{4}^{\prime}+t_{5}^{\prime}+t_{6}^{\prime}\right) / 6$ & $484 \mathrm{~h}$ & $105 \mathrm{~h}$ \\
\hline The average up time & $\mathrm{MTBF}=\left(T+t_{1}+t_{2}+t_{3}+t_{4}+t_{5}+t_{6}\right) / 6$ & $976 \mathrm{~h}$ & $1646 \mathrm{~h}$ \\
\hline The mean time to repair after & MUT $=t_{1}+t_{2}+t_{3}+t_{4}+t_{5}+t_{6}$ & $736 \mathrm{~h}$ & $3912 \mathrm{~h}$ \\
\hline The availability & $\mathrm{D}=\mathrm{MTBF} /[\mathrm{MTBF}+\mathrm{MTTR}]$ & 0.66 & 0.94 \\
\hline The average rate & $\lambda=1 / \mathrm{MTBF}$ & $0.001 \mathrm{~h}^{-1}$ & $0.0006 \mathrm{~h}^{-1}$ \\
\hline The repair rate & $\mu=1 /$ MTTR & $0.002 \mathrm{~h}^{-1}$ & $0.009 \mathrm{~h}^{-1}$ \\
\hline
\end{tabular}

\section{Analysis and Discussions of the Results of the Study of the Two Engines}

It can be seen that the top three repairs accounting for $80 \%$ of all repairs that cause a lot of trouble for the company are: filling up on oil, changing the fuel injector and changing the cylinder head. These are the priorities to be taken in the appropriate maintenance plan. Thus, try first to tackle these first three defects and seek to clarify the real causes of these.

The comparative study gave us the following results, presented in Table 3.

Table 3. Comparative study between the engines DM04 and DL07

\begin{tabular}{|l|c|c|c|}
\hline Type & DM04 & DL07 & Ratio \\
\hline Failure frequency & 54 & 9 & 6 \\
\hline Repair costs & 1889188.15 & 430900.424 & 4.38 \\
\hline MTTR & $484 \mathrm{~h}$ & $105 \mathrm{~h}$ & 4.60 \\
\hline MTBF & $976 \mathrm{~h}$ & $1646 \mathrm{~h}$ & 0.59 \\
\hline The availability & $66 \%$ & $94 \%$ & 0.70 \\
\hline$\lambda$ & 0.0010 & 0.0006 & 1.66 \\
\hline$\mu$ & 0.002 & 0.009 & 0.22 \\
\hline
\end{tabular}

According to the results of the study (comparative Table 3), the actual state of health of this type of motor (DM04) compared to the other generation (DL07) could be characterized: exploitation of engine type DM04 is seriously reviewed by the company officials.

\section{Conclusion}

Following the results of the comparative analysis performed on the engines of the two locomotives (DM04 and DL07), we note that the DM04 type no longer meets the expected performance and these repair costs are more than triple compared to the DL07 type. The maintenance of this locomotive is more expensive than its exploitation, which lets us suggest its stop. In addition, the managers of maintenance services in companies are not always able to strictly defend their operating budget and even less their contribution to the efficiency of the company.

We are aiming for additional training for maintenance staff at the company level.

\section{References}

1. Aib A., Chaib R., Aib S., Verzea I. (2014): Promoting a sustainable organizational culture in a company: The National Railway Transport Company. Journal of Rail Transport Planning \& Management, ISSN 2210-9706, Vol. 4, issue 4, p. 87-114, https://doi.org/10.1016/i.jrtpm.2015.01.001

2. Monchy F., Vernier J.-P. (2010): Maintenance. Méthodes et organisations. Dunod, ISBN 978-2-10-055061-6, 3 $3^{\text {rd }}$ edition, Paris, France

3. Mohamed El Koujok (2010): Contribution au pronostic industriel: intégration de la confiance à un modèle prédictif neuro-flou. Diss. 2010. University of Franche-Comté, France

4. Chaïb R., Taleb M., Benidir M., Verzea I., Bellaouar A. (2014): Failure: A Source of Progress in Maintenance and Design. Physics Procedia, ISSN 1875-3892, Vol. 55, p. 185-191, https://doi.org/10.1016/i.phpro.2014.07.027, http://www.sciencedirect.com/science/article/pii/S1875389214000893 
5. Chaib R., Verzea I., Benidir M. (2010): Contribution to the Performance Improvement of a Boring Mill Operation Machine. Recent, ISSN 1582-0246, Vol. 11(2010), no. 3(30), p. 173-179, http://www.recentonline.ro/030/Chaib_R30.pdf, Brasov, Romania

6. Matmat M. (2010): For a comprehensive approach to reliability assessment in microsystems. PhD thesis, University of Toulouse, Issued by the National Institute of Applied Sciences; specialty: Micro and Nano-Systems

7. Letot C., Dehombreux P. (2015): Modèle de maintenance adaptative imparfaite pour des équipements sujets à la dégradation (Imperfect adaptive maintenance model for equipment subject to degradation). $11^{\mathrm{e}}$ Congrès internationaux de génie industriel - CIGI2015, Québec, Canada

8. Zwingmann X. (2005): Modèle d'évaluation de la fiabilité et de la maintenabilité au stade de la conception (Evaluation Model for Reliability and Maintainability at the Design Stage). PhD thesis, Université Laval, Quebec, Canada

9. Pallas J.-L. (2003): Guide pratique d'entretien et de réparation des moteurs Diesel (Practical guide of maintenance and repair of diesel engines). Editions Loisirs Nautiques, $\mathrm{N}^{\circ} 2267-1991$

10. Chaib R., Verzea I. (2012): The establishment of maintenance plans to the needs of production. International Journal of Research and Reviews in Méchatronic Design and Simulation (IJRRMDS), ISSN: 2046-6234, Vol. 2, no. 2, p. 161-164

11. Bouilla N., Boulhart H., Soualah A. (2014): Comparative technical-economic study between two locomotives DL07 and DM04. Bachelor's degree in Transportation Engineering, University of Constantine 1, Algeria

12. Chaïb R., Bellaouar A., Benidir M., Ion Verzea I. (2010): For a better control of the availability of the industrial equipments. Recent, ISSN 1582-0246, Vol. 11(2010), no. 1(28), p. 7-10, http://www.recentonline.ro/028/ Chaib R28.pdf, Brasov, Romania

13. Taleb M., Chaib R. Verzea I., Cozminca I. (2013): Master Maintenance: It Is to Ensure the Availability of Such Equipment and Its Production. International Journal of Engineering Research and Development, p-ISSN: 2278800X, Vol. 6, issue 12, p. 15-20, https://www.academia.edu/10978012/article publi\%C3\%A9 